\title{
Study on the location of the emergency storage for processed grain based on multi-objective location model ---take a direct-controlled municipality as an example
}

\author{
Qi Wang ${ }^{1, \text { a }}$, Jian jun $\mathrm{Han}^{2, \mathrm{~b}}$ \\ ${ }^{1}$ Hanan University of Technology, China \\ ${ }^{2}$ Hanan University of Technology, China

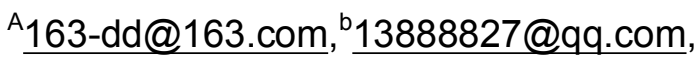

\begin{abstract}
Keywords: processed grain, emergency reserve, multi-objective, location model, Genetic algorithm Abstract: Under the background of the current frequent emergencies, the problem of the processed grain emergency storage has the practical significance and theoretical value. This paper considers the facility location efficiency for processed grain emergency storage and coverage radius demands satisfaction differences, the cost and other factors. This paper builds a multi-objective location model, proposes using genetic algorithm to solve problem and takes a country as an example to demonstrate the proposed model and algorithm. This research could provide certain reference for the location selection of emergency logistics reserve.
\end{abstract}

\section{Introduction}

Nowadays, various factors lead to the rapid growth of emergencies, such as, the population increase and economic development, the rapid progress of urbanization and the global climate's continuous deterioration etc. The grain storage is an important support to deal with the emergencies. Besides, the processed grain is not only irreplaceable important supplies for everyday life, but also necessary for saving the stricken people's life and for disaster-relief work. According to this, the construction of processed grain emergency storage is of great urgency.

Emergency facility location issues have been one of the most important areas of facility location research. At present, we have established the model that using a minimum of facilities to solve the problem of the emergency storage location for processed grain ${ }^{[1]}$. Such as, D. R. Shier aims to minimize the distance between the network nodes and put forward the absolute center model of single facility location ${ }^{[2]}$. Snyder and Daskin take the minimum cost as the objective to construct facility location mode ${ }^{[3]}$. In addition, temporary first aid center and shelter are planned to minimize the transportation time by Wei Yi. JinZhang, Qili Guo and other scholars build the emergency logistics facility location model with the goal of maximizing the satisfaction ${ }^{[4-5]}$. Besides, Junhua Xiao and Chunjing Ge study the location issue of the duplicate cover emergency facility ${ }^{[6-7]}$. In conclusion, the issue of emergency facility location has a defeat of simplex target. Due to the perish ability and high-cost of the processed grain in the process of transportation and conservation. This paper aims to construct a location model of minimum cost, shortest time and maximum satisfaction in a comprehensive and practical way. It also provides the scientific theory for improving the emergency management system.

\section{Regional profiles and repository location model}

Regional profile. The city is located in the north of the North China Plain, junction of the Yanshan mountains and the Taihang Mountains. Mountainous area accounts for $62 \%$ of the total area and has lots of fault zone. Therefore the geological and geographical environment is more complex. As a large city, it has many kinds of potential public emergencies, such as road traffic accident, fire, group events and political events. As a large city in the north, it is mainly in the face of natural disasters, such as earthquakes, dust storms, haze and so on. There are many types of potential public events, for it is located in 6 degrees, 7 degrees, 8 degrees earthquake intensity areas. 


\section{Location model configuration of finished grain emergency reserve.}

Basic assumptions of the mode. The problem of the storage of grain reserves usually involves two types of sites, one is the demand site, which is called the demand site in this paper; the other one is the facility site, that is, the finished grain emergency reserve. The model makes the following assumptions: (1)Assuming the facilities and demand points are discrete and site like, the demand sites are $\mathrm{m}$, and the number of candidate facilities is $\mathrm{n} ;(2)$ As the construction costs and maintenance costs are relatively high, so the number of facility site to be limited, for the p; (3) The construction cost, operation and maintenance cost of the reserve site of the finished grain emergency reserve can be estimated; (4) The distance between the location site and the demand site of the emergency storage depot is a straight line distance between two sites; (5)Transport distance, transport demand and transportation costs are proportional;(6)Must select the repository in the given alternative established repository.

\section{Definition of model parameters.}

$\mathrm{i}$ :Demand point, I:Demand point of the whole; j: Facilities, J:Facilities of the whole; $\mathrm{m}_{\mathrm{i}}$ :The Demand site I population; $\mathrm{L}_{\mathrm{i}}$ : The $\mathrm{i}$-th site of demand for food per day; $\mathrm{L}_{\mathrm{ij}}$ : $\mathrm{J}$-th alternative repository emergency demand sites to the $\mathrm{i}$-th number of transport emergency supplies; $\mathrm{d}_{\mathrm{ij}}$ : Demand site $\mathrm{i}$ to the site of facility $\mathrm{j}$; $\mathrm{q}_{\mathrm{ij}}$ : Coverage radius difference parameter demands satisfaction; $\mathrm{C}_{\mathrm{ij}}$ : $\mathrm{J}$-th alternative facility to the demand site $i$ of transportation costs; $F_{j}$ : The cost of the land and the cost of construction of the reserve facility; $C_{j}$ : The $j$-th alternative facility creates the operating costs of the reserve.

The establishment of the model. Based on the above analysis, the problem description, the basic conditions and the basic parameters are determined, constructing the mathematical model of multi-objective maximum coverage, As follows:

(1) For the objective function to maximize the total satisfaction of the demand sites covered;

$$
\max Z=\sum_{i=1}^{m} \sum_{j=1}^{n} m_{i} * q_{i j} * x_{i j} \quad \text { (1) among } \quad \mathrm{q}_{\mathrm{ij}}=\frac{\max \left\{\mathrm{d}_{\mathrm{ij}}\right\}-\mathrm{d}_{\mathrm{ij}}}{\max \left\{\mathrm{d}_{\mathrm{ij}}\right\}}
$$

(2) For the lowest for the objective function, the total cost of the system, including the transportation cost and the cost of the reserve;

$$
\min Z=\sum_{\mathrm{i}=1}^{\mathrm{m}} \sum_{\mathrm{j}=1}^{n} C_{i j} * d_{i j} * L_{i j}+\sum_{i=1}^{n}\left(F_{j}+C_{j}\right) * y_{j}\left(C=C_{i j} * d_{i j} * L_{i j}\right)
$$

The transportation cost per unit distance of $\mathrm{C}_{\mathrm{ij}}$ can be regarded as a fixed value, and easy to set up $\mathrm{C}_{\mathrm{ij}}=1$

(3) 、(4)Makes the selected facility site J cover the demand site i; to strengthen the service efficiency of the facilities, to ensure that each demand site can be provided by a service site at most, eliminating the problem of repeated coverage between facilities.

$$
\begin{aligned}
& X_{\mathrm{ij}} \leq \mathrm{y}_{\mathrm{j}}, \forall \mathbf{1}, \mathrm{j}, \\
& \sum_{j=1}^{n} x_{i j} \leq 1, \forall i,
\end{aligned}
$$

(5)、(6)Indicates that the shipment of emergency supplies can meet the demand of each demand site; that the amount of material transported $\mathrm{L}_{\mathrm{ij}}$ is non-zero constraints;

$$
\begin{aligned}
& \sum_{j=1}^{n} L_{i j} \geq L_{i} \\
& \sum_{j=1}^{n} x_{i j} \leq 1, \forall i,
\end{aligned}
$$

(7) Specify the number of selected facilities as $p$;

$$
\sum_{j=1}^{n} y_{j}=p
$$


(8) 、 (9)Indicates that the location decision is a $0-1$ constraint, either established or not; indicates that the site decision is a $0-1$ constraint, that is, the demand site is either covered or not covered.

$$
\begin{aligned}
& \mathrm{xij}_{\mathrm{i}} \in\{0,1\}(i=1,2,3 . . m ; j=1,2,3 . . . n) \\
& y_{j} \in\{0,1\}(j=1,2,3 . . n)
\end{aligned}
$$

\section{The optimal allocation of the model}

The basis of configuration and description of the algorithm. Based on the model, we optimize the city's emergency stockpile configuration of the finished food. According to the development plan of the city's "twelfth five-year" period social security, in accordance with the demand for a city's past daily consumption ration $0.44 \mathrm{Kg} /$ calculation, district resident population data obtained by municipal statistics yearbook 2015. Usually this article assumes that all government agencies is located as the demand sites and candidate facilities, road driving distance between them is represented the distance between requirements and facilities, data from the measured distance function of "Google Map". Maximum coverage model is a typical NP-Hard problem. Therefore, this article uses genetic algorithm to solve the repertory's location model about the finished food. The algorithm can be divided into two stages. Firstly, multi-objective model is transformed into single objective model. The second phase is solving by genetic algorithm.

Fig. 1 point diagram of the objective function and facilities

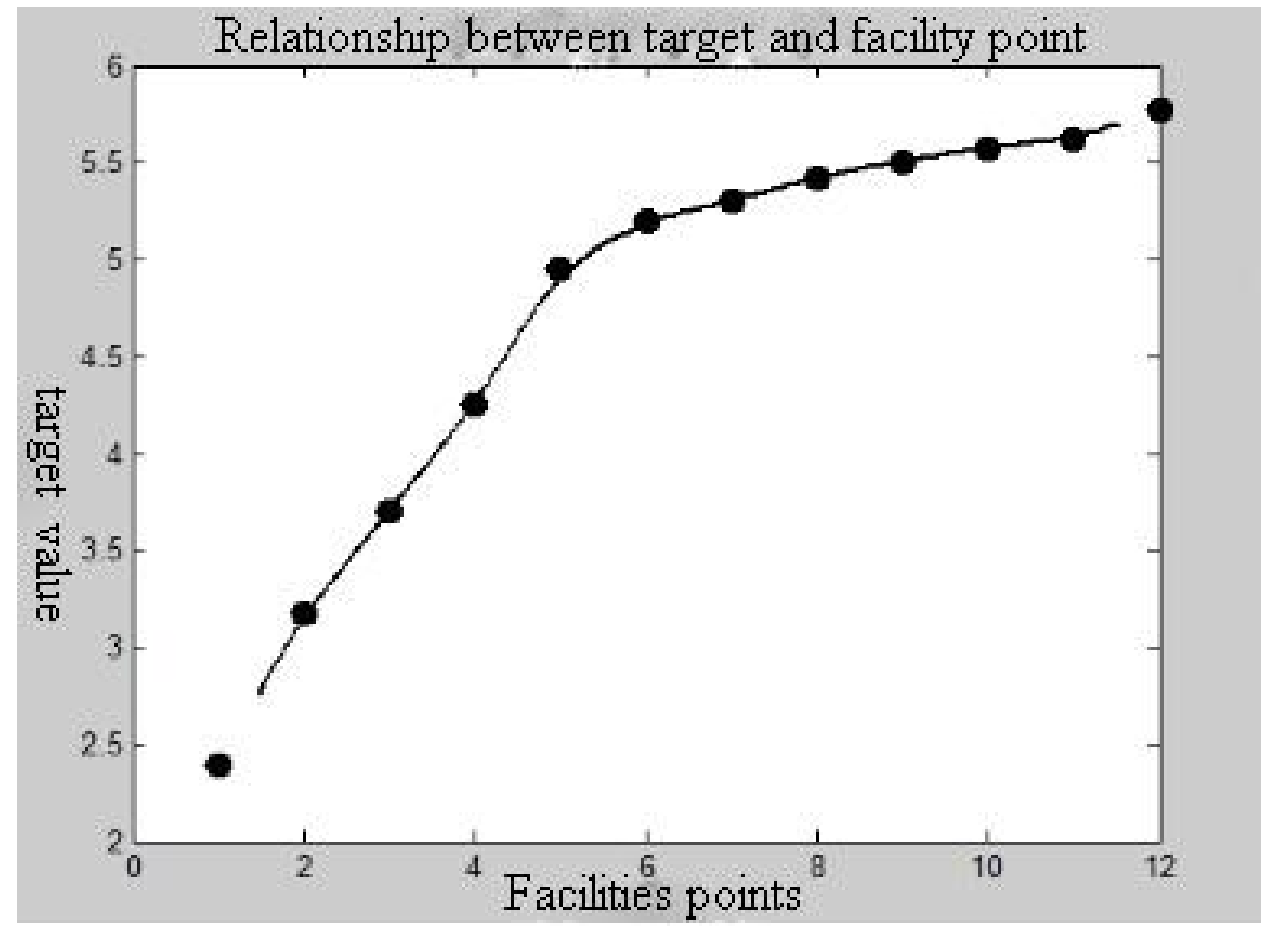

Configuration results. According to the model, combined with the principle of the algorithm in Matlab 2015 programming and running the model. When a city has 16 jurisdictions, excluding four densely populated, the central city traffic becomes complex. The number of emergency reserves of refined grain can be selected in the range of 1-12, obtained a storage location number allocation result. As shown in Fig. 1, the inflection point of the objective function value is between the number of facilities points 4-6, compromising to determine a city refined grain emergency reserves for the number of five. The construction sites of the five reserves obtained by the genetic algorithm program are $\mathrm{E}, \mathrm{H}, \mathrm{K}, \mathrm{I}$ and $\mathrm{O}$ jurisdictions. The demand for services, the farthest service distance and coverage satisfaction of each reserve are shown in Table 2.

It can be seen from Table 2 that the spatial distribution of the five reserves is reasonable. The resident population of the area which including the jurisdiction $\mathrm{E}$, I and the five districts covered by 
them have reached 14.2 million, accounting for $65.4 \%$ of the total population in the city. Because of high population density and high probability of emergencies, the establishment of product grain emergency reserve in these two sites will provide strong support to the emergency response of the city's emergency. The results show that the area served by the emergency reserve has balanced distribution. And it is conducive to the dispatch and distribution of relief supplies when emergencies occur. In addition, it can be gotten that E and I mainly serve the central and the most developed areas of a city. $\mathrm{H}$ main service to a southern part of the city and the northern region is served by $\mathrm{K}$ and $\mathrm{O}$.

Table2 The results of the allocation of five refined grain emergency reserves in a city

\begin{tabular}{|c|c|c|c|}
\hline Repository facility selection & Provide service demand points & Farthest service distance / unit & Satisfaction \\
\hline $\mathrm{E}$ & $B 、 F 、 D 、 E$ & $11.3 \mathrm{~km} / \mathrm{D}$ & $100 \%$ \\
\hline $\mathrm{H}$ & $\mathrm{L} 、 \mathrm{G} 、 \mathrm{H}$ & $21.7 \mathrm{~km} / \mathrm{G}$ & $99.60 \%$ \\
\hline $\mathrm{K}$ & $P 、 M 、 K$ & $35.6 \mathrm{~km} / \mathrm{M}$ & $97.60 \%$ \\
\hline I & C、A、I & $19.9 \mathrm{~km} / \mathrm{A}$ & $99.80 \%$ \\
\hline $\mathrm{O}$ & $\mathrm{J} 、 \mathrm{~N} 、 \mathrm{O}$ & $35.3 \mathrm{~km} / \mathrm{N}$ & $97.50 \%$ \\
\hline
\end{tabular}

\section{Conclusion}

Location of emergency reserves for finished grains is an important guarantee for life when emergency occurs. The essence of the problem is a multi-objective and multi-constrained NP problem. This paper is mainly based on multi-objective programming method in order to construct location model of reserves. The number of repository locations and the configuration results calculated by Matlab 2015, and the results are in line with the actual needs of the emergency reserve. Moreover, this method provides new ideas for emergency logistics location problem in the face of emergencies.

\section{References:}

[1] Adel A, White. Probabilistic Formulation of the Emergency Service Location Problem[J]. Journal of the Operational Research Society,1978,29(12):1167.

[2] D. R.Shier. Optimal Locations for a Class of Nonlinear, Single-Facility Location Problems on a Network[J]. Operations Research,1983,31(2):292 .

[3] Snyder L V, Daskin M S. Reliability Models for Facility Location: the Expected Failure Cost Case[J]. Transportation Science,2005,39(3):400-416.

[4] Yi W, Özdamar L. A dynamic logistics coordination model for evacuation and support in disaster response activities[J]. European Journal of Operational Research, 2007, 179(3): 1177-1193.

[5] Guoqi Li, Jin Zhang, Sijing Liu. Multi-objective programming model of urban emergency logistics facility location [J]. 2011,47 (19) : 238-241.(In Chinese)

[6] Junhua Xiao, Yunxian Hou .The construction of multi-level covering location model about emergency supplies reserve [J]. Journal of statistics and decision, 2012 (23) : 45-48. (In Chinese)

[7] ChunJing Ge, Xia Wang, Xianjun Guan. In view of the emergency facilities of a major incident repeated covering location model and algorithm [J]. Journal of management and management, 
2011, 20 (5) : 50-56. (In Chinese) 